\title{
JURISPRUDENCIA ANDALUSÍ EN EL ALQUILER DE VIVIENDAS
}

\author{
Pedro Cano Avila
}

Otro de los capítulos más importantes, desde el punto de vista social, que forman parte de los Tratados notariales, es el dedicado al arrendamiento de las viviendas, en primer lugar, y del resto de edificios urbanos o rurales, en segundo lugar ${ }^{1}$. En general, todos los contratos que se ocupan de los arrendamientos --ya de edificios, ya de tierras-- y de los alquileres --ya de servicios de personas, ya de utilidades de bienes muebles, semovientes y de navíos-sobresalen de los demás contratos por su propia naturaleza y por su incidencia en el bienestar y progreso de la sociedad musulmana, particularmente en el ámbito económico.

Con anterioridad me he ocupado del contrato de alquiler de servicios de personas, conocido como i $\hat{y} \bar{a} r a$ e $i s t i^{D} \hat{y} \overline{a r}$ de forma general, y como $\hat{y} u^{c} l$ por sus características especiales $^{2}$. Y ahora creo de interés publicar este estudio del arrendamiento de viviendas como complemento suyo.

\footnotetext{
${ }^{1}$ Las fuentes y bibliografía básicas que he utilizado para este estudio han sido: SAḤNŪN/IBN AL-QĀSIM, alMudawwana al-kubrà, en M.E. Sāsì (ed.) (El Cairo 1323 H/1905 JC), 16 tomos en 8 vols., XI, 44-104, 147-201 (en adelante citaré por Mudawwana); analysé par G.H. BOUSQUET, "La Moudawwana (Recension de $\mathrm{Sah}{ }^{\circ}$ noun)", A.I.E.O. XVIII-XIX (1960-61), 73-165, núm. 1543-1609 y 1643-1726 (en adelante $L a$

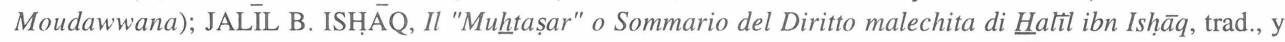
not., I. GUIDI e D. SANTILLANA (Milano 1919), 2 vols., II, 503-538 (citaré JALIL); Encyclopédie de I'Islam, nouvelle édition, (Leyde-Paris 1960) V, 129, s.v. Kirä ${ }^{\text {, }}$ DELCAMBRE (citaré E.I. ${ }^{2}$ ); E.I. ${ }^{2}$, III, 1042 1043, s.v. Idjīar, TYAN; J.M. FORNEAS, "Datos para un estudio de la Mudawwana de Sahnūn en al-Andalus", Actas del IV Coloquio Hispano-Tunecino (Madrid 1983), 93-118 (citaré Datos); M. DEL NIDO Y TORRES, Derecho musulmán, (Tetuán 1927), 367-379 (D. musulmán); J. LOPEZ ORTIZ, Derecho musulmán, (Barcelona-Buenos Aires 1932), 208-210 (Derecho); C. QUIROS RODRIGUEZ, Instituciones de Derecho Musulmán. (Escuela Malekita), (Ceuta 1942), 101-109 (Institucionès); G. SURDON, Précis élementaire du Droit Musulman de l'école malékite d'Occident, (Tanger et Fez 1935), 125-127 (Précis); J. SCHACHT, Introduction au droit musulman, (Paris 1983), 131-132 (Introduction); L. MILLIOT, Introduction à l'étude du Droit musulman, (Paris 1953), 640 (Introduction); D. SANTILLANA, Istituzioni di Diritto Musulmano Malichita con riguardo anche al sistema sciafiita, (Roma 1926, 1938), 2 vols, II, 231-285 (Istituzioni); M.A. ABDUR RAHIM, The Principles of Muhammadan Jurisprudence according to the Hanafi, Maliki, Shafi ${ }^{i}$ and Hanbali Schools, (London-Madras 1911), 316-317.

2 P. CANO, "Alquiler de servicios de personas en el reino nazarí de Granada", Homenaje al Pr. J.M. Fórneas, (En prensa).
} 
El arrendamiento o alquiler (kir $\vec{a}$ ) de los edificios destinados a viviendas pertenece al campo jurídico de las $m u^{c}$ amalāt, es decir, de las relaciones civiles existentes entre las personas. Se trata de un contrato conmutativo ( ${ }^{c} a q d m u^{c} \bar{a} w a d$ ), íntimamente relacionado con el de compraventa $\left(b a y^{c}\right)^{3}$, en cuyo ámbito se integra, por el que ambas partes contratantes se transfieren recíproca y voluntariamente dos valores patrimoniales equivalentes.

Este contrato sinalagmático, por el cual una parte contratante puede usar y beneficiarse de las utilidades de un bien inmueble perteneciente a la otra parte firmante del instrumento público, consiste en esencia en la compraventa o transmisión legítima del usufructo de ese bien, es decir, de su disfrute temporal, a cambio de una contraprestación determinada y equivalente, que puede consistir en numerario, en productos naturales, o en otros bienes. El período del contrato debe estar determinado también, así como la cantidad a pagar, si lo exige el propio tipo de contrato.

Pero todas estas características se pueden ordenar en los siguientes elementos esenciales, que se requieren para la constitución de este tipo de contratos conmutativos:

1. Los contratantes (al-mutacāaidāni).

2. El objeto del contrato ( $a l-m a^{c} q \bar{u} d^{c}$ alay-hi).

3. El consentimiento de los sujetos, recogido en una fórmula específica (șiga).

4. Las diversas fórmulas y cláusulas contractuales $(\breve{s u r u \bar{t}})$ que garantizan la efectividad jurídica y judicial del documento.

\section{Los contratantes.}

Ambas partes contratantes deben ofrecer plena responsabilidad y capacidad jurídicas para contraer obligaciones personales; para ello han de alcanzar la mayoría de edad y tener capacidad mental suficiente. Deben cumplir con los deberes y derechos que imponen, de forma general, las normas que regulan el contrato de compraventa; por ejemplo, conocer la vivienda alquilada interior y exteriormente, y estar informado de los defectos que tenga. El arrendador o propietario del bien es conocido por mukrî, rabb y șạhib al-dār, y el arrendatario o inquilino por muktarì y säkin.

\section{El objeto del contrato.}

Para la ley musulmana tanto el bien inmueble alquilado, como la contraprestación entregada, tienen la consideración de objetos contractuales. El inmueble debe ser útil, determinado y legítimo, mientras que la contraprestación claramente especificada se puede entregar bien al contado, al principio o al final del período acordado, bien a plazos. Puede hacerse su entrega en metálico, en productos mercantiles elaborados en esa vivienda, en productos naturales transformados en ese edificio, o en otros bienes muebles.

\footnotetext{
${ }^{3}$ P. CANO, "Contratos de compraventa en el reino nazarí de Granada, según el Tratado notarial de Ibn Salmūn", al-Qantara, IX(1988), 323-351 (citaré Contratos).
} 


\section{La fórmula $(\operatorname{sig} a)$ de la voluntad contractual.}

La fórmula empleada en el documento recoge la expresión del consentimiento y la voluntad de ambas partes contratantes. Ello supone el resultado de la correspondencia existente entre la oferta $(\bar{I} \hat{y} \bar{a} b)$ y la aceptación (qabul) de ambos. Si faltara esta correspondencia no existiría contrato y, además, se rescindiría el que estuviera en vigor ${ }^{4}$. Tanto el texto árabe presentado por Ibn al ${ }^{-}{ }^{c}$ Att $\bar{a}$, como por Ibn Salmūn, o el que edita L. Seco de Lucena, presenta una fórmula breve y simple: "Iktarà Fulān ${ }^{u n} \min$ Fulānin $\hat{y} a m \vec{I}^{c}$ aldār..."5.

\section{Las diversas fórmulas y cláusulas contractuales.}

De estas fórmulas depende la efectividad jurídica del instrumento público redactado, por lo que la ausencia de alguna de ellas supone la inmediata reducción de derechos, que podría haber adquirido cualquiera de las dos partes contratantes. Además de las que he citado anteriormente, cabe resaltar las que se ocupan de los límites y dependencias de los edificios arrendados, el tipo de moneda dada, la entrega y toma de posesión física y jurídica del precio, la transmisión de dominio del inmueble alquilado, el conocimiento y aceptación de ese inmueble, la apreciación del alcance jurídico del acuerdo, los testimonios y la fecha.

En relación con estas cláusulas, debo advertir que el texto del Formulario compuesto por Ibn al-c Attār (m.399/1009), y el del contrato del s. XV traducido por Seco de Lucena son bastante completos; en cambio, el texto del Formulario de Ibn Salmūn presenta un número inferior de fórmulas, lo cual no llega a impedir la producción de los efectos jurídicos deseados por ambos contratantes, evidentemente.

En el comentario jurídico (fiqh) realizado por Ibn al- ${ }^{c}$ Ațtāa , sólo existe un tema: el de la limpieza interior del inmueble arrendado, incluida la letrina. Cita lo que la Mudawwana recoge sobre el particular. Sin embargo, por su parte Ibn Salmūn se extiende mucho más y expone las opiniones acordes o divergentes de los juristas mālikíes más importantes, como fueron: Mālik (m.179/795), Ibn al-Qāsim (m.191/806), Ašhab (m.204/820), c̄̄sà b. Dìnār (m.212/827), Ibn al-Māŷišūn (m.212 ó 214/827 u 829), Muțarrif (m.220/835), Ibn Hạaìb (m.238/853), Ibn al-S̆aqqāq (m.426/1035), Abū c̄̄mrān al-Fāsì (m.430/1039), Ibn Daḥhūn (m.432/1040), Abū Bakr b. 'A Abd al-Raḥmān (m. 435/1043), al-Šāriqi (m.456/1064), Ibn Rizq (m.477/1085), Abū l-Ḥasan al-Lajmì (m.478/1085), Ibn Sahl (m.486/1093), Ibn Farây (m.497/1104), Ibn Rušd (m.520/1126), e Ibn al-Ḥâŷyy (m.529/1134).

4 E.I. ${ }^{2}$, I, 328-330, s.v. ${ }^{c} A k d$, CHEHATA.

5 Véase IBN AL- ${ }^{\mathrm{C}} \mathrm{ATT} \overline{\mathrm{A}} \mathrm{R}$, Formulario notarial hispano-árabe, por el alfaquí y notario cordobés Ibn al- ${ }^{c} A t t a \bar{r}$, (s. X), (kitāb al-Wațāo iq wa-l-siŷillāt), en P. CHALMETA Y F. CORRIENTE (eds.), (Madrid 1983), 192-193 (citaré Formulario); P. CANO, Contratos conmutativos en la Granada nazarí del siglo XIV, según el Formulario notarial de Ibn Salmūn (m.767/1366), (Granada 1987), Tesis Doctoral, 2 vols., 512-535 (citaré C. conmutativos), para la cual he usado la edición de El Cairo 1301 H. vol. I, 267-273; L. SECO DE LUCENA, Documentos arábigo-granadinos, (Madrid 1961), 74, doc. n³8, también se edita texto árabe. 
Los temas que trata con más profundidad Ibn Salmūn son:

1. Las dos modalidades de alquiler de viviendas: a) la acordada por un tiempo determinado y fijo, y b) la periódica o prorrogable.

2. El pago de todo el precio del arrendamiento, o no.

3. La toma de posesión física y su problemática.

4. La actualización o subida del precio del alquiler, si se prolongara la estancia más allá de lo acordado.

5. La propiedad de los frutos dados por los árboles del inmueble, y de otros bienes accesorios.

6. Los desperfectos sufridos en la vivienda.

7. El momento del pago del alquiler.

8. La muerte, o la quiebra económica del arrendatario.

9. La posterior venta de la casa con alquiler en vigor.

10. Causas de rescisión del contrato.

Parte de estos interesantes temas también los recoge en su Risāla el gran jurista norteafricano (o andalusí, según J. Riosalido) Ibn Abì Zayd al-Qayrawānī ${ }^{6}$.

Dicho esto, creo que lo mejor sería dar paso ya a la traducción del capítulo correspondiente al Tratado de Ibn Salmūn, donde también se presenta su opinión personal y la jurisprudencia granadina de su época.

\section{TRADUCCION}

Capítulo de los arrendamientos (akriya) de las viviendas, de las tierras y otros inmuebles (según ed. El Cairo, 1301 H., vol., I, p. 267) ${ }^{7}$.

El arrendamiento ( $k i r \bar{a}^{\supset}$ ) de las viviendas y de otros inmuebles con techo (rib $\bar{a}^{c}$ ) es lícito durante un tiempo determinado, por un alquiler determinado ${ }^{8}$. En virtud de ello se redactaría un

\section{CONTRATO $\left({ }^{C} A Q D\right)$}

"Fulano arrienda (iktarà) a Mengano toda la casa situada en tal sitio, cuyos límites son tales, con todos sus derechos (huqūq) y dependencias (hurum) y con la totalidad de sus utilidades (marāiq $)$. Arrendamiento (iktir $\vec{a}^{\supset}$ ) legítimo acordado por una duración de un año completo, contado a partir de este momento, siendo el inicio tal día y suponiendo, en concepto de arrendamiento por el año mencionado, la cantidad de tanto, que hará efectiva

\footnotetext{
${ }^{6}$ IBN ABİ ZAYD AL-QARAWĀNI, al-Risāla, trad. fr. ed. not. et index par L. BERCHER, La Risala ou Epître sur les éléments du dogme et de la loi de l'Islâm selon le rite mâlikite, (Alger 1983), 215-217; estudio y trad. por J. RIOSALIDO, Compendio de Derecho Islámico [Risāla ft-l-Fiqh], Madrid 1993, 122-123. IBN YUZAYY, alQawānin al-fiqhiyya, (Lìbiyā-Tūnis 1982), 279-283, en cuatro interesantes capítulos.

7 Véase CANO, C. conmutativos, II, 512-535.

8 En el contrato a tiempo fijo la determinación de sus elementos principales, el tiempo y el precio, es fundamental. NIDO, D. Musulmán, 367-370.
} 
cuando acabe el año, o a lo largo del mismo. El arrendatario (muktarî) toma posesión (nazala) de lo arrendado para usarlo y obtener provecho de sus utilidades, después de haberlo visto y quedar perfectamente informado de todo lo que le concierne. En virtud de lo cual, se emite el correspondiente testimonio invocable contra ambas partes, en tal fecha".

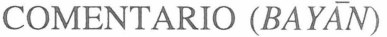

Este arrendamiento acordado por un tiempo determinado obliga a las dos partes, por lo que ninguna de las dos puede anularlo, ni liberarse de sus obligaciones, sin el consentimiento de la otra, hasta que acabe el período de tiempo acordado, como sucede con la compraventa $\left(b a y^{c}\right)$ porque es igual a ella ${ }^{9}$. En todos los inmuebles urbanos es lícito contratar un arrendamiento mensual o anual ${ }^{10}$, de modo diferente al primero. En virtud de ello, se escribiría lo que sigue textualmente:

"Fulano arrienda a Mengano la casa situada en tal lugar, o la tienda ubicada en tal sitio, con todos sus derechos y aprovechamientos $\left(\operatorname{man} \bar{a} \bar{i}_{i}^{c}\right)$ desde este momento. Este contrato se acuerda mensual o anualmente por tal cantidad al mes o al año, que hará efectiva obligatoriamente al finalizar cada mes, a lo largo del año o a finales del mismo. El arrendatario (muktarî) toma posesión de lo arrendado..." y sigues así hasta completar el contrato como anteriormente se ha expuesto.

Cada uno de los dos puede anular este arrendamiento cuando quiera, si no se hubiera especificado un tiempo determinado ${ }^{11}$, como sucede en el caso de que el arrendatario hubiera terminado el tiempo calculado de permanencia en lo arrendado.

A veces surgen discrepancias en el primer mes o en el primer año, por lo que aparece la siguiente cuestión: ¿Había obligación de pagar ese período parcial, o no? ${ }^{12}$. Sobre el particular existen dos corrientes de opinión. La primera de ellas mantiene que no hay obligación, en el caso de que no se hubiera mencionado de forma concreta el mes en cuestión; siendo ésta la postura de Ibn al-Qāsim ${ }^{13}$, quien se basó en Mālik ${ }^{14}$. La segunda

\footnotetext{
${ }^{9}$ Algunas causas extraordinarias interrumpen la validez del contrato, como por ejemplo, cuando el propietario tiene necesidad imperiosa de habitar la casa alquilada, o a veces la insolvencia. LOPEZ ORTIZ, Derecho, 208. 10 JALīL, II, 528.

${ }^{11} \mathrm{El}$ arrendamiento de las viviendas no se puede rescindir aunque se haya determinado mensual o anualmente, si el precio del mismo ya ha sido pagado. JAL $\bar{I} L$, II, 528-529; QUIROS, Instituciones, 102; NIDO, D. musulmán, 376.

12 La obligación de pagar el importe del arriendo nace del hecho de que el arrendatario haya podido disfrutar de su derecho, aunque no lo haya disfrutado. NIDO, D. musulmán, 376.

$13{ }^{c}$ Abd al-Raḥmān Ibn al-Qāsim (m.191/806). Fue quien mejor interpretó las enseñanzas de Mālik b. Anas, y tuvo gran influencia en los juristas norteafricanos y andalusíes. Fue el inspirador de la obra titulada $K$. al Mudawwana. CANO, C. conmutativos, II, 681-682; CANO, Contratos, 341.

${ }^{14}$ Mālik b. Anas (m.179/795). Epónimo de la escuela jurídica malikí, que tuvo gran ascendiente en el Norte de Africa y al-Andalus. Autor de uno de los libros más antiguos de jurisprudencia musulmana, el Kitäb alMuwatta ${ }^{\supset}$. CANO, C. conmutativos, II, 689; CANO, Contratos, 346.
} 
opinión propugna la obligación del pago del arrendamiento; siendo mantenida por Muțarrif ${ }^{15}$ e Ibn al- Mâŷišūn ${ }^{16}$, quien se basa en el anterior.

En el caso de que el arrendatario pagara parte del //I, 268// arrendamiento, tendría que obligarse al pago de todo el arrendamiento por ese tiempo, punto en el que coinciden los juristas. Lo mismo sucede si el dueño de la casa impusiera como condición (ǐstarața) que, si aquél se asienta un sólo día, tiene que pagar todo el mes y, como último recurso, se atendría a la costumbre local ( $\left.{ }^{c} u r f\right)$, que se entendería como si se llegara a contratar con esa condición $(\breve{s} a r t)^{17}$. Si ninguno de los dos determinara el comienzo del arrendamiento, se tomaría como fecha de partida la del contrato, a no ser que se hubiera fijado una fecha concreta ${ }^{18}$.

Si en el contrato no se expresara nada sobre la toma de posesión ( $\mathrm{nazl}$ ) de la casa y hubiera terminado el plazo, momento en el que alega (idd $\left.c^{c} \grave{a}\right)$ el arrendatario (muktarî́) que él no había tomado posesión ( qabada) de la casa, ni se había establecido en ella, se tomaría en cuenta su opinión $(q a w l)$. Si no poseyera ninguna prueba documental (bayyina), debería prestar juramento y no estaría obligado a pagar parte alguna del arrendamiento, salvo que se demostrara que la había ocupado (nazala $)^{19}$.

Ibn al-Mâŷišūn se refirió a la casa, al baño, al molino y a edificios semejantes a éstos, contando el caso del arrendatario que, después de un año, reclama diciendo que no había tomado posesión de ello ni lo había usado, y dijo que la opinión a tener en cuenta sobre el particular sería la del dueño $(r a b b)$, si pudiera demostrar su arrendamiento efectivo. Sobre este caso la jurisprudencia $\left(q a d \vec{a}^{3}\right)$ se atiene a la primera opinión ${ }^{20}$.

Si hubiera vencido el plazo de tiempo y el arrendatario prolongara su estancia y siguiera usando el edificio, surgiría la siguiente cuestión: ¿Habría que considerar esto como una prolongación del contrato anterior, respetando todas sus características y cláusulas, o se tomaría el arrendamiento medio o equivalente $(k i r \vec{a}$ al-mit $l)$ ? ${ }^{21}$. Sobre el particular existen dos posturas.Concretamente la primera está defendida por Ibn al-Qāsim, según nos transmite

${ }^{15}$ Muțarrif b. ${ }^{c}$ Abd Allāh (m.220/795). Alfaquí y tradicionista natural de Medina. Sobrino y discípulo de Mālik, y representante, junto a Ibn al-Mâŷǐ̌ūn, de una corriente de opinión opuesta a la egipcia de Ibn al-Qāsim. CANO, C. conmutativos, II, 692; CANO, Contratos, 348.

$16{ }^{c}$ Abd al-Mālik b. ${ }^{c}$ Abd al- ${ }^{c}$ Azìz, conocido por Ibn al-Māŷǐ̌ūn (m.212 ó 214/827 u 829). Miembro de una familia de juristas y discípulo de Mālik, de quien trnasmitió su Muwațta ${ }^{\circ}$. Se enfrentó juridicamente hablando a Ibn al-Qāsim y sus seguidores. Alumno predilecto suyo fue el granadino Ibn Hạabìb. CANO, C. conmutativos, II, 679.

17 Si se ha acordado el arrendamiento según un período fijo, el contrato obliga a las partes desde la fecha en que es perfecto hasta el fin de dicho período, salvo que se haya condicionado la facultad de rescisión. Mudawwana, XI, 155, n 1653; QUIROS, Instituciones, 108; SANTILLANA, Istituzioni, II, 237; JALIL, II, 528.

${ }^{18}$ Mudawwana, XI, 156, nº 1654.

19 JAL $\overline{I L}$, II, 538.

20 Se trata de la opinión de Ibn Salmūn, seguramente en representación del malikismo andalusí del s. XIV.

${ }^{21}$ Es el arrendamiento debido en los inmuebles de su categoría y características. Un caso semejante, pero en la tierra, puede verse en Mudawwana, XI, 176, 180, nº 1682-1684, 1691; SANTILLANA, Istituzioni, II, 245. 
${ }^{c} \overline{\mathrm{I}} \mathrm{àa}^{22}, \mathrm{y}$ cree que se debe tomar el arrendamiento medio, a no ser que disminuya respecto al primer arrendamiento, caso en el que se consideraría como prolongación del arrendamiento primero; pero si aumentara, debería prestar juramento su dueño, expresando no estar satisfecho del primer arrendamiento y se impondría un precio actualizado.

Ibn al-Mâŷi išūn dijo que todo tipo de casas, tiendas o edificios semejantes a éstos que tuvieran llaves y se pudieran cerrar, no pueden cambiar en relación con el arrendatario; es decir, que tienen que respetar lo anteriormente establecido. Así pues, el arrendatario sólo tendría que pagar a tenor del primer arrendamiento. Esta opinión no se aplicaría en el caso de la tierra ni de los inmuebles integrados en su grupo general.

Si en la casa hubiera fruto y lo impusiera bajo condición (ištarata) el arrendatario, habiendo comenzado a madurar, sería lícito $\left(\hat{y} \bar{a}^{\top} i z\right)$ hacerlo, ya fuera mucha o poca la cantidad de fruto. Por otra parte, si no hubiera empezado a madurar, siendo su valor, después de descontar el precio del riego y de las labores necesarias, una cantidad equivalente al tercio del precio del arrendamiento por el plazo de tiempo contratado, o menos aún, y hubiera llegado a madurar antes de completar tal plazo, también sería lícito imponerlo como condición. Ahora bien, si no se ajustara a estas condiciones no sería lícito. Por el contrario, si hubiera llegado a madurar después de agotarse el plazo, no sería lícito imponerlo como condición ${ }^{23}$.

Tampoco se permitiría imponer bajo condición parte del fruto, fuera poco o mucho, según Ibn al-Qāsim, así como no se podría condicionar ningún adorno de la espada ${ }^{24}$, en el caso de que fuera dependiente, porque es una parte del fruto y no cesa el perjuicio (darar) con la condición de que sea sólo una parte de él; sin embargo, si quisiera podría comprarlo. En cambio, As̆hab ${ }^{25}$ considera lícito tanto el caso del fruto como el del adorno de la espada, diciendo que si se le permite //I, 269// imponer bajo condición su totalidad, con mayor razón se podría condicionar parte del mismo. Por su lado, Abū l-Hasan al-Lajmit ${ }^{26}$ dijo que si el arrendamiento fuera por varios años, siendo la mayoría (del fruto) dependiente sólo en algunos años; es decir, sin serlo en todos los años, no se permitiría imponerlo bajo

22 čsà b. Dinār (m.212/827). Toledano asentado en Córdoba como una de las grandes figuras del malikismo andalusí. Muftí y cadí célebre por su inquietud intelectual. Autor del K. al-Hidāya. CANO, C. conmutativos, II, 687-688.

${ }^{23}$ Los frutos maduros que aún están en el árbol pertenecen, por regla general, al propietario del terreno. Si se incluyeran en el alquiler, tendrían que establecer dos contratos: uno de alquiler del inmueble y otro de compraventa de los frutos. En cambio, si no estuvieran maduros, se podrían condicionar, pero el contrato estaría sujeto a las reglas de la usura y de la aleatoriedad que impone el Derecho musulmán a determinados productos, como los comestibles. QUIROS, Instituciones, 108; Mudawwana, XI, 147, $\mathrm{n}^{\circ} 1643$.

${ }^{24}$ JALILL, II, 512; Mudawwana, XI, 59, nº 1554.

${ }^{25}$ Ašhab b. ${ }^{c}$ Abd al- ${ }^{c}$ Azìz (m.204/820). Jurista egipcio discípulo de Mālik e Ibn al-Qāsim, entre otros. En numerosas ocasiones sus opiniones son contrarias a las de Ibn al-Qāsim, por lo que fue muy criticado. CANO, C. conmutativos, II, 661-662; CANO, Contratos, 341.

26 cAlì b. ${ }^{c}$ Alì al-Lajmì (m.478/1085). Jurista malikí de Qayrawān con una gran independencia jurídica. CANO, C. Conmutativos, II, 689 . 
condición, aunque se hubieran acercado o igualado los años, alternando los dependientes con los otros.

Si la casa tuviera palomar o colmena de abejas y el arrendatario quisiera condicionarlo, no podría hacerlo ${ }^{27}$, aunque hubiera escasas unidades, como sucede en el caso de los árboles, porque eso no se considera como parte de la misma casa, y el beneficio de ambos es desconocido. Así pues, aquello quedaría fuera del objeto de la compraventa $\left(b^{c} y^{c}\right)$, porque lo que se compra es la cosa o nuda propiedad (raqāba) en aquel contrato; en cambio, en éste serían los frutos (gallāt).

El arrendamiento de la casa que conlleve la condición de la toma de posesión (qabd) del arrendatario después de un año de la fecha del arrendamiento es lícito, aunque se pagara al contado el arrendamiento ${ }^{28}$. Dijeron algunos juristas que si se impusiera la condición por una duración superior a un año, no sería lícito. En cambio, Ibn Hạäib ${ }^{29}$ defendía su legitimidad por varios años, aunque pagara al contado el arrendamiento.

Por su parte, el arrendatario podría introducir en la casa los animales de carga que quisiera $^{30}$, podría construir un horno de pan y realizar otras actividades diferentes; salvo si las molestias ocasionadas a los vecinos fueran insoportables, o se lo hubiera condicionado el propietario (șāhib), por lo que ya no podría hacerlo. Pero si a pesar de ello se empeñara en realizar lo prohibido, sería responsable (damman) de los perjuicios ocasionados ${ }^{31}$. Entre los derechos del arrendatario también se encuentran el que le permite llevar a la casa a las personas que él quiera para que habiten en la misma, y el que le permite subarrendar la casa a quien quiera, siempre que no derivara de ello un perjuicio evidente ${ }^{32}$.

Por su parte, el dueño tendría que encargarse de los desperfectos que sufriera el edificio ${ }^{33}$ y también tendría que preocuparse por la cuidadosa limpieza del tejado, entre otras

27 QUIROS, Instituciones, 108; SANTILLANA, Istituzioni, II, 239; CANO, Contratos, 344.

28 Cuando se vende una casa por un precio inferior al real, con la condición de entregarla al cabo de un año, reservándose el usufructo de la misma, el contrato de compraventa es considerado como un contrato de alquiler, porque la diferencia existente entre el valor real y el precio pagado representa el alquiler de la misma.

29 Abū Marwān ${ }^{c}$ Abd al-Malik b. Habìib b. Rabì c a al-Sulamì, al-Ilbììi, conocido por Ibn Habìb (m.239/854) Autor prolífico, destacado en jurisprudencia, historia, tradición y medicina. Compuso la Wādiḥa. Véase CANO, Contratos, 346, nota 68, a cuya bibliografía habría que añadir IBN HAB İB, Mujtașar fi l-tịbb (Compendio de medicina), introd. ed. crítica y trad. por C. ALVAREZ DE MORALES y F. GIRON (Madrid 1992).

${ }^{30}$ Mudawwana, XI, 159, $\mathrm{n}^{\circ} 1658$.

31 Como otros, el derecho de propiedad tiene determinados límites. Consiste el darar en ocasionar ciertos perjuicios al vecino abusando del propio derecho. Producen molestias los humos, ruidos, malos olores, etc. SANTILLANA, Istituzioni, I, 266; II, 302.

32 El disfrute de la cosa arrendada no ha de ser forzosamente personal. LOPEZ ORTIZ, Derecho, 209; SANTILLANA, Istituzioni, II, 243.

${ }^{33}$ Ibn Salmūn se aparta en este punto de la doctrina de Ibn al-Qāsim y de Jalîl, adhiriéndose a la opinión de Ibn Rušd y Sahnūn. El propietario debe garantizar el usufructo pacífico de la cosa alquilada, al que tiene derecho el arrendatario. Mudawwana, XIV, 78, n² 2246; SANTILLANA, Istituzioni, II, 239-240; JAL $\overline{I L}$, II, 530, 533. 
obligaciones semejantes ${ }^{34}$. Ibn al-Qāsim se contradijo en lo que se refiere a la limpieza de la letrina, porque en una ocasión se mostró favorable a que esa obligación recayera sobre el dueño de la casa ( $r a b b$ al-dār), pero en otra ocasión dijo que era una obligación del arrendatario (muktarì). Algunos juristas dijeron que era posible que su opinión no fuera contradictoria, sino que se podría tratar de que el dueño limpiara la suciedad que hubiera en la casa antes del arrendamiento, y entonces no existiría desacuerdo en que recayera en el dueño de la misma en este caso y, por lo que se refiere al arrendatario, se tratara de que éste fuera responsable de ello durante el tiempo del arrendamiento. Por otra parte, tanto Mutarrif como Ibn al-Mây išūn dijeron que los dos contratantes se atuvieran a la tradición local (sunnat albalad).

Sería lícita la rescisión por mutuo acuerdo (iqāla) del arrendamiento, si éste no se hubiera pagado al contado ${ }^{35}$. En el caso de que se hubiera pagado la parte obligatoria del período de tiempo, quedando otra parte sin pagar, sería lícito rescindirlo por el tiempo que aún no se había pagado, exceptuando el período que se había pagado ya. Si se pagara todo el período de tiempo obligatorio, habitando el edificio sólo parte de ese tiempo, no sería lícita la rescisión del contrato según Mālik, dijo Ibn al-Qāsim ${ }^{36}$, porque aquello se considera como la venta de mercancías, por lo que cabe preguntarse: ¿Se pone a la venta sólo una parte de las mismas? Ibn Habìb dijo que aquello era un arrendamiento y un préstamo (salaf) y que tampoco era lícito contratarlo por una deuda (dayn), pues se convertiría en una deuda por otra ${ }^{37}$.

Si se pagara en efectivo parte del arrendamiento, sin que se señalara si se partía //I, 270// desde el primer mes o desde otro, y luego ambos discutieran (tan $\left.\bar{a} z a^{c} \vec{a}\right)$ por ese motivo, se resolvería pagando todo el año, aunque no se pusieran de acuerdo en la fecha del pago del arrendamiento.

Si la cuestión estuviera en el límite del comienzo (hulūl) del segundo plazo (naŷm), la opinión $(q a w l)$ válida sería la del dueño de la casa, pero tendría que añadir a ello su juramento (yamin) y tomaría el correspondiente arrendamiento del arrendatario, tanto si el pago fuera a principios de mes, como a finales, al cabo de dos meses, de tres o al final del año, ya que se aplica la misma norma ( hukm) para todos ellos.

En el caso de que el propietario eludiera su cumplimiento, la opinión válida sería la del arrendatario o inquilino, pero tendría que prestar juramento ${ }^{38}$ y quedaría liberado; a no ser que se incluyera en el contrato una cláusula por la que él no quedara liberado del arrendamiento, sino por la presentación de una prueba documental [bayān $(?)=$ bayyina $]$, y

\footnotetext{
34 Estos gastos, entre otras obligaciones genéricas, no pueden ser impuestos al arrendatario. En cambio, si se especificase cada una de ellas, sí sería legítimo. Mudawwana, XI, 150, 151, nº 1644-1647; JALİL, II, 532.

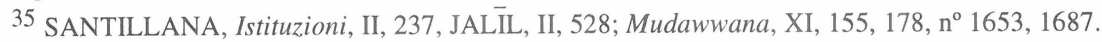

${ }^{36}$ Mudawwana, XI, 155, $\mathrm{n}^{\circ} 1653$.

${ }^{37}$ En definitiva, Ibn Habìib está de acuerdo con Ibn al-Qāsim.

${ }^{38} \mathrm{El}$ juramento en estos casos tiene un valor decisivo.
} 
no por la conclusión del plazo y la entrada en vigor de otro; por esta razón sería necesaria la prueb̉a documental (bayyina). En caso contrario, sería merecedor de una sanción (gurm).

Quien arrienda (iktarà) una casa mensual o anualmente y paga el alquiler de un mes determinado o de un determinado año, obtiene la exoneración, porque se ha recibido el pago del mismo.

Si no se señalara en el contrato el momento del pago y ambos discreparan sobre el mismo, diciendo el dueño de la casa que correspondía a principios del mes y el inquilino (sākin) que a finales del mismo, ambos tendrían que atenerse a la tradición local ( ${ }^{c} u r f$ albalad) en lo que se refiere al arrendamiento y, si no hubiera tradición, tendría que pagar calculando un día tras otro, ya fuera el arrendamiento mensual, ya anual, de forma que entonces la opinión válida sería la del arrendatario sobre el tiempo transcurrido, salvo en el último mes o en el último año, en el que se tendría en cuenta la opinión del dueño de la casa (șâhib al-dār), siempre que se llevara a cabo en el segundo límite o plazo del mismo.

Ibn Habìib dijo que si se prolongara la estancia aproximadamente hasta un mes en un contrato mensual, y hasta un año en un contrato renovado anualmente, el arrendatario estaría protegido por la ley con su juramento (yamin).

Si hubiera desacuerdo en la cantidad del arrendamiento, estando en vigor éste, ambos contratantes tendrían que jurar y lo anularían.

En el caso de que hubiera vivido en el edificio parte del año, ambos podrían anular el resto tras haber jurado, teniendo que pagar en concepto de arrendamiento la cantidad proporcional a lo que se reconociera que no había pagado ${ }^{39}$. Si sucediera tras haberse completado el año, sin que se hubiera pagado, la opinión a tener en cuenta sería la del arrendatario con su juramento, si fuera verosímil. Si hubiera desacuerdo en el período de tiempo y el dueño hubiera cobrado en metálico el arrendamiento, la razón la tendría el arrendador (mukrî) o dueño de la casa, con su juramento, se hubiera establecido o no el arrendatario. En el caso de que no hubiera pagado al contado el arrendatario, estando en vigor el arrendamiento, ambos tendrían que prestar juramento y lo anularían ${ }^{40}$.

Si uno de ellos retrocediera en sus pretensiones, la opinión válida sería la del otro, después de prestar juramento sobre el particular. Si sucediera después de haber residido parte del año, podrían anularlo por el resto, después de que ambos juraran, y se pagaría en proporción al tiempo transcurrido a tenor de lo que con anterioridad se había jurado sobre el caso.

Si // I, 271 // ambos discreparan en la finalización del período, la opinión válida sería la del arrendatario, en lo que se refiere a la cantidad de tiempo que restara, pero también tendría que prestar juramento.

\footnotetext{
39 SANTILLANA, Istituzioni, II, 237.

${ }^{40}$ Mudawwana, XI, 165-166, 181, nº 1668-1669, 1691; JAL İL, II, 538.
} 
Si discreparan sobre los objetos de madera o algo parecido que hubiera en la casa, se resolvería entregando los bienes inmuebles (t $\underline{t} \bar{b} i t)$ al dueño de la casa y los muebles al arrendatario ${ }^{41}$.

Si se desplomara parte de la casa arrendada durante el período de disfrute del inquilino, el dueño no la tendría que restaurar, pero se debería interesar por el suceso y, en el caso de que el mencionado derrumbamiento no hubiera perjudicado al arrendatario, ni hubieran disminuido las prestaciones del arrendamiento, no podría reclamar (lā maqāl la-hu). Ahora bien, si hubieran disminuido en algo las prestaciones de la casa arrendada, sin que llegaran a impedir su residencia en ella, tendría que rebajarse el precio del mismo en proporción a la disminución de sus prestaciones, y a ello no puede negarse el dueño ${ }^{42}$. Si se hubiera derrumbado gran parte del edificio e impidiera la residencia en él, el arrendatario podría optar, con total libertad, por seguir en el edificio, reduciendo de su arrendamiento la cantidad proporcional al perjuicio recibido, o bien por abandonar el edificio sin tener obligación alguna respecto al arrendamiento ${ }^{43}$.

En los Mas $\vec{a}^{3} i l$ de Ibn al-Hị̂ŷy $\hat{y}^{44}$ se plantea un caso sobre la persona que arrienda una casa y, después de cumplirse el período de arrendamiento, el arrendatario reclama manifestando que la casa había estado derrumbada durante dos meses antes de terminar el período, sin que pudiera aprovecharse de ella; y, además, el caso del que, por el mismo motivo, reclama después de transcurrida parte del período de tiempo, estando el arrendamiento en vigor, y se dice que los dos supuestos son iguales y que la opinión válida en el asunto sería la del dueño de la casa, o del molino, con su juramento; a no ser que el arrendatario presentara una prueba documental. Esto es lo manifestado en la Mudawwana ${ }^{45}$; pero, por su parte, Ibn Habīb pensaba que la opinión válida era la del morador (sākin). Otros dicen que la opinión de Ibn Habìib no está en contra de lo anterior, porque él habla de un año no determinado; en cambio, Ibn al-Qāsim se refiere, en la Mudawwana, a un año concreto.

\footnotetext{
${ }^{41}$ La transmisión de la cosa alquilada debe comprender todos los accesorios y dependencias que contribuyan al efectivo usufructo de la misma y formen parte de ella. SANTILLANA, Istituzioni, II, 239.

42 LOPEZ ORTIZ, Derecho, 210; Mudawwana, XI, 163, 165, nº 1667, 1668.

43 Sin embargo, Jalìl, basándose en la Mudawwana, afirma que si el arrendatario permanece en la casa alquilada, debe pagar todo el alquiler, por lo que Ibn Salmūn se aparta de las primitivas normas de la doctrina malikí. Mudawwana, XI, 163-165, nº 1667-1668.

44 Muhammad Ibn al-Hậ̄ŷy al-Tuŷ̀ìì (m.529/1134). Alfaquí malikí que ocupó el cargo de cadí supremo de Córdoba en dos ocasiones. Tuvo gran influencia en el malikismo andalusí y escribió unas Nawāzil al-Aḥkām muy útiles. Murió asesinado en la aljama cordobesa. CANO, C. conmutativos, II, 675-676; CANO, Contratos, 344 .

45 Obra que contiene y explica la doctrina jurídica malikí, de importancia capital para sus seguidores. Fue redactada por Saḥnūn, según las respuestas dadas por Ibn al-Qāsim a las cuestiones jurídicas que le eran planteadas por sus discípulos. FORNEAS, Datos, 93-118.
} 
Se le preguntó a Ibn Rušd ${ }^{46}$ sobre la persona que arrendó una casa durante varios años concretos, a plazos (nuŷum), pero murió o se declaró en quiebra (fallasa), por lo que surgió la siguiente cuestión: ¿Serían ineludibles los plazos restantes hasta completar el contrato o, por el contrario, sólo se pagarían los correspondientes al tiempo en que estuvo residiendo en la casa? ${ }^{47}$.

Y respondió: Sobre esta pregunta existen dos corrientes de opinión en la Escuela Malikí (madhab). La más correcta de ambas es la que considera que los plazos deben ser anulados por su muerte o por su declarada insolvencia (falliss). Así pues, se anularían y no podría reclamar el dueño el pago del alquiler correspondiente al tiempo restante, porque él no había dado nada a cambio, siendo éste el fundamento $(a s ̣ l)$ de Ibn al-Qāsim, quien no juzga que la toma de posesión $(q a b d$ ) de una casa, para ser habitada, sea una toma de posesión para residir en ella por todo el período, aunque la casa fuera segura o estuviera en buenas condiciones, y está de acuerdo con la Escuela en que el arrendamiento fuera anulado por su muerte, pero los herederos (warata) tomarían posesión de ello, en su lugar, como nuevos inquilinos ${ }^{48}$, salvo que el dueño de la casa dijera que no aceptaba la responsabilidad ( $\underline{\text { dimma }}$ ) que ellos le ofrecían y, por tanto, podría rescindir el arrendamiento y tomar su casa, siguiendo la opinión de los malikíes respecto a la insolvencia (tafliss), sin que tuviera que entregarla ni hacer cuentas con los deudores ( guram $\left.\vec{a}^{\mathfrak{}}\right)$.

En la opinión de Ibn al-Qāsim hay confusión porque está de acuerdo con un fundamento // I, 272 // diferente al suyo, que es el de la doctrina de As̆hab, porque Ašhab considera que la toma de posesión del primer arrendamiento ${ }^{49}$ se considera como una toma de posesión para todo el período.

Se le preguntó también a Ibn Rušd ${ }^{50}$ acerca de la persona que arrienda una casa o una tierra, y muere antes del término del arrendamiento. En este caso, ¿se debe cobrar la deuda dejada tomándola de la herencia (tirka)?

Y respondió: No está permitido que se pague al arrendador (mukrî̉) tomando lo que corresponda de la herencia del fallecido, en concepto de los años que queden pendientes de pago en la tierra, en la que no es lícito pagar con dinero al contado, por lo que se cumpliría la sentencia que dispone que los herederos, si quisieran, podrían vincularse al arrendamiento con sus bienes, o bien subarrendar dicha tierra por el resto del período pendiente, de tal

\footnotetext{
46 Muhammad Ibn Rušd (m.520/1126). El mejor alfaquí de su tiempo. Muftí, Șāhị al-salā y cadí supremo de Córdoba. Su influencia en la jurisprudencia malikí fue enorme. Autor de las Muqaddimāt y del Bayān. CANO, C. conmutativos, II, 684; CANO, Contratos, 343.

47 La insolvencia del arrendatario permite al propietario rescindir el contrato. JAL $\bar{L} L$, II, 308, 519-520; QUIROS, Instituciones, 103; NIDO, D. musulmán, 374.

48 Se refiere al contrato de arrendamiento acordado por la persona que luego ha fallecido. SANTILLANA, Istituzioni, II, 245.

49 Se trata del acordado por el que había fallecido.

${ }^{50}$ La pregunta va dirigida a Ibn Rušd, aunque el texto editado del ${ }^{c} I q d$ no lo mencione.
} 
forma que si no llegan con sus bienes a cubrir el precio del arrendamiento, que había contratado el fallecido, se tomaría de la herencia el montante que faltara para completar el arrendamiento y le darían al arrendador la cantidad correspondiente al arrendamiento, cuando llegara el momento, año tras año ${ }^{51}$.

Esta norma también recae en la casa, de acuerdo con las opiniones que se consideran correctas, y es la misma norma a la que se atienen los seguidores (madhab) de As̆hab. Sin embargo, creo que algunos sabios $(\breve{s} u y \overline{u j})$ consideran que se debe pagar al contado todo el valor del arrendamiento al dueño del inmueble, aunque sea tomándolo de la herencia del arrendatario, porque creen que es una obligación ineludible a pesar de su muerte, como

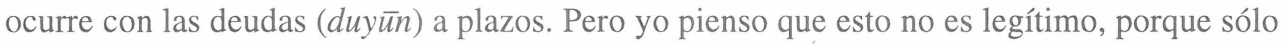
es ineludible aquello que se toma (qabada) a cambio de otra cosa y, en consecuencia, no se debe pagar algo que aún no se ha recibido a cambio de ese precio, puesto que son utilidades $\left(\right.$ manāfic $i^{c}$ recibidas poco a poco ${ }^{52}$.

Si el dueño vende la casa arrendada después de haberla arrendado, habría que tener en cuenta si la vende al propio arrendatario o a otra persona ${ }^{53}$.

En el caso de que la vendiera a otra persona ( $a \hat{y} n a b \hat{1})$, y ésta no estuviera informada del arrendamiento ya existente, adolecería de vicio $\left({ }^{c} a y b\right)$ y, en consecuencia, podría optar por devolverla o por conservarla. Pero si estuviera informado de ello, no podría devolverla y le correspondería el arrendamiento que recibía el vendedor, quien no tendría ningún derecho sobre el particular, salvo que anteriormente lo hubiera impuesto bajo condición. En el caso de que lo hubiera condicionado, sería necesario pagar el arrendamiento al vendedor, en su totalidad o parcialmente, por el resto del tiempo que faltase, o una parte del mismo. Hay unanimidad en que no puede recibir ese arrendamiento, salvo que este pago suponga menos de un dinar, siendo el precio (taman) en oro, según lo que hemos expuesto anteriormente en el capítulo de los contratos de compraventa $\left(b u y \bar{u}^{c}\right)$.

Si no se tuviera que pagar parte alguna del arrendamiento al vendedor, porque hubiera transcurrido todo el tiempo, o bien si lo condicionara el vendedor, surgirían discrepancias representadas en dos opiniones. Por un lado, Ibn Rizq ${ }^{54}$ y otros sabios lo declaran lícito y, por otro, se argumenta que no se debía pagar el arrendamiento al vendedor después de la venta, porque el arrendatario residiría en la casa ya propiedad (milk) del comprador, de tal

51 SANTILLANA, Istituzioni, II, 245.

52 Esta opinión es la expresada por Ibn Salmūn, quien coincide plenamente con Ibn Rušd.

53 Ibn Zarb (m.381/991 ) emitió una fetua acerca de quien alquila su tierra durante diez años y luego quiere venderla, en la que dictamina que no le está permitido venderla hasta que concluya el arrendamiento. Véase P. CANO, "Dictámenes jurídicos del sevillano Ibn al-Makwì", Boletín de la Asociación Española de Orientalistas, XXIX (1993) 141-154.

54 Ahmad b. Muhammad, conocido por Ibn Rizq (m.477/1085). Ilustre jurisperito y tradicionista cordobés cuue destacó en mas $\bar{a}^{\supset} i l$ y nawāzil. Fue mušāwar, muftí y maestro de importantes juristas. CANO, C. conmutativos, II, 683-684. 
forma que se consideraría como si el vendedor, al vender la casa, hubiera liberado al arrendatario del contrato que existía entre ambos. Ibn Rušd // I, 273 // dijo que esta opinión era la más correcta y la mejor, en cuanto a argumentación se refiere, aunque hay quien no está de acuerdo con él, siendo ésta la opinión de Ibn al-Qāsim, recogida en la Dimyātiyya ${ }^{55}$, en la que se dice que eso no era lícito.

Algunos sabios dijeron que el comprador podía establecerlo bajo condición o no, y añadió Ibn Rus̆d, continuando el comentario sobre este asunto, que había discrepancias en el caso de la persona que arrienda una casa por todo el año y más tarde la vende, antes de finalizar el plazo. Algunos dicen que la venta de la casa se había realizado un día después de lo que ambos habían contratado, y que el comprador se haría cargo de la obligación contraída desde entonces, teniendo que pagar el valor del arrendamiento por el resto del año. Otros dicen que la venta está viciada $(f \bar{a} s i d)$, salvo que el vendedor hubiera excluído el resto del período de tiempo. También hay quien opina que no podría ocupar la casa sino después de cumplir el período de arrendamiento, sin que pudiera obtener nada del arrendamiento, salvo que lo hubiera condicionado. Respecto a esto hay quien dice que era lícito, pero otros opinan que la venta estaría viciada, si el comprador tuviera conocimiento del arrendamiento y, además, aunque no lo supiera el comprador, existiría vicio $\left({ }^{c} a y b\right)^{56}$. En consecuencia, o bien podría permanecer en la casa con la condición de no obtener ninguna parte del arrendamiento, o bien podría devolverla.

En el caso de que vendiera la casa al arrendatario, dijeron Abū Bakr b. ${ }^{c} \mathrm{Abd}$ al-Raḥmān ${ }^{57}$ y $A \overline{b u}{ }^{c}$ Imrān al-Fāsì ${ }^{58}$ que se rescindiría el contrato, porque aún no había terminado el período del arrendamiento. Por su parte, dijo Ibn Sah1 ${ }^{59}$ que la opinión de Abū Bakr se

55 Se trata de la obra por excelencia del jurista ${ }^{\mathrm{c}}$ Abd al-Raḥmān b. Abì Ya ${ }^{\mathrm{c}}$ far al-Dimyāți (m.226/841), discípulo de Mālik. CANO, C. conmutativos, II, 712.

56 Véase la nota 53.

57 Abū Bakr Aḥmad b. ${ }^{c}$ Abd al-Rahmmān al-Jawlānì (m.432 ó 435/1040 ó 1043). Llegó a ser el mejor dișcípulo de Abū l-Ḥasan al-Qābisì (m. 403/1013). Muftí destacado por sus conocimientos de la Mudawwana. CANO, C. conmutativos, II, 666.

${ }^{58} \mathrm{Ab \overline {u }} \overline{{ }^{2}} \overline{m r a ̄ n}$ al-Fāsì (m.430/1039). Alfaquí fiel seguidor de Sahnūn. Viajó a al-Andalus y Oriente en busca de ciencia. CANO, C. conmutativos, II, 657-658.

59 Ibn Sahl (m.486/1093). Jurista giennense establecido en Córdoba, donde presidió la šūrà. Llegó a ser cadí en varias ciudades peninsulares y norteafricanas. Autor del Dīwān al-ahkām al-kubrà. CANO, C. conmutativos, II, 684-685; R. DAGA PORTILL,O, "Aproximación a la obra al-Ahkām al-kubrà del cadí ${ }^{c} \bar{I}$ sà b. Sahl", M.E.A.H., XXXVI(1987), 237-249. 
acercaba más a la verdad. Además, manifestaron Ibn Daḥhūn ${ }^{60}$, Ibn al-S̆aqqāq ${ }^{61}$ y al-S̆āriqii ${ }^{62}$ que si la comprara a condición de que el arrendamiento fuera reducido, no sería lícito, pero añadió Ibn Daḥḥ̄nn, salvo que prescribiera el arrendamiento después de realizada la compraventa, sin que esto estuviera incluido en el cuerpo del contrato, caso en el que sería lícito. Por su parte, dijo al-Šāriqi que eso lo había autorizado Ibn Faraŷy ${ }^{63}$, hecho que constituía un error, porque compraría la casa y el arrendamiento por el precio que había hecho efectivo.

Ibn Sahl dijo que la opinión de éstos conduce a que la adquisición ( $\left.\breve{s i r} \bar{a}^{\supset}\right)$ no anula el arrendamiento; así pues, ésta es una cuestión sobre la que hay que reflexionar.

60 c Abd Allāh b. Yahyà, conocido por Ibn Dahḥūn (m.432/1040). Muftí y mušāwar de reconocido prestigio. Destacó en la ciencia del notariado y fue fiel seguidor del jurista sevillano Ibn al-Makwi. P. CANO, "El jurista sevillano Ibn al-Makwi. (s. X-XI)", Philologia Hispalensis, VII(1992), 123-140, concretamente 138 (Jurista).

$61{ }^{c}$ Abd Allāh b. Sa ${ }^{C} \overline{1}$ d, conocido por Ibn al-S̆aqqāq (m.426/1035). Muftí, mušāwar, y cadí de varias coras andalusíes. Fiel seguidor del jurista sevillano afincado en Córdoba Ibn al-Makwì (m.401/1010). CANO, Jurista, 137-138.

62 c Abd Allāh b. Mūsà, conocido por al-Š̄ariqì. (m.456/1064). Célebre jurista y tradicionista toledano, discípulo de grandes expertos en la ciencia del notariado, y maestro del cadí Ibn Sahl. CANO, C. conmutativos, II, 694.

63 También conocido por Ibn al-Talla $\bar{a}^{\mathrm{c}}$ (m.497/1104). Jurista cordobés, autor de un Tratado de Derecho notarial titulado al-Wața ${ }^{\circ}$ iq al-mujtașara. CANO, C. conmutativos, II, 672. 
